So that's what I did.

'I remember when I first got him, doc. He was such a little mongrel. It was love at first sight.'

I swallowed hard, recalling the day Pimpant bounded into our lives. You try telling your child that he cannot have the puppy he's embracing with all the love of which a 6-year-old is capable. We kept the dog. That was 12 years ago.

For 5 long bloody minutes that dog went Eee eee eee eee eee.

The yelps grew softer - the canine ones, that is. Kip died in pain.

'Can I give you something, Cyril?'

'No no, I got work to do. I'm takin' 'im home with me. He's going out the back.'

I didn't want to know how the miner's tired body could carve out a grave from the grey scree behind his shack. I just wanted the corpse off my hands.

I went home and yapped at the kids for making too much noise and almost kicked the dog.

I'll never do that again. I mean it. When people ask me to put down their animals, I send them to Cyril Johanssen, who's done a total volte-face. God knows what the poor man suffered during the 2 months nobody saw him. Whatever it was turned his heart. When his grief released him - or he entered the next phase - Cyril bought a .22 and set himself up as an animal liberator, saying it's quicker and more humane to put a bullet through their heads. Perhaps he's right.

But that's not quite the end of the story. The old miner hates me now. Should I have acted differently? Would Cyril still go to the other doctor and cross the street to avoid me if I had refused to put down his dog?

Now Pimpant's hip dysplasia is so bad he drags his hind legs.

And I'm dragging my feet.

\section{Susan Woldenberg Butler}

\title{
Tips and tricks in performing a systematic review
}

\section{CHAPTER 3}

\section{Reference management and identifying search terms and keywords}

Previously ${ }^{1}$ you have identified a number of articles that you think should be included in your systematic review. Now begins the process of identifying keywords and keeping on top of the logistics of performing a review.

When performing a systematic review you usually have a large number of references which you need to process and organise. To do this it is worth investing in reference management software mainly because they can handle a very large number of references quickly and efficiently without being plugged into the internet.

Currently there are two styles of reference management software, webbased (for example, Refworks), and my preference; offline packages, (for example, Endnote).

Now begins the process of identifying search terms and keywords. Search terms are words which are included in the search strategy, and they appear in the title and abstract of the article. However, the keywords and $\mathrm{MeSH}$ are not so easy to spot, sometimes you can see the author selected keywords which index the articles, but typically the $\mathrm{MeSH}$ headings are not visible as they are retrospectively applied. To easily see the $\mathrm{MeSH}$ of your article you need the help of your reference management software.

After you have familiarised yourself with your software, you need to locate all your previously identified articles on MEDLINE and import them into your reference database. When importing references it is imperative that you import reference information as well as the keywords/MeSH and the abstract.
The next step is to print your references which must include your title, abstract and keywords/MeSH. To print all of these fields you need to edit the output style in your software and add the abstract and keyword fields to the output. All that's left to do is go through each reference and identify each term in the title and abstract which typifies the content of the article, and reflects your research question.

Next chapter: building a PICO search strategy.

\section{Adrian Sayers}

\section{REFERENCE}

1. Sayers A. Tips and tricks in performing a systematic review. Preliminary evidence gathering: snowballing and reverse snowballing. Br J Gen Pract 2007; 57(542): 759 . 